\title{
Situación del menor campesino que estudia y trabaja en el sector agrario en Tuta, Boyacá
}

\section{Situation of the minor peasant that works and studies in the a gricultural sector in Tuta, Boyaca}

\author{
María Elcy Guzmán Quintero \\ E-mail: marelcy2004@yahoo.com \\ Universidad Pedagógica y Tecnológica de Colombia (UPTC)
}

Resumen.- Se estudió la situación de menores campesinos del municipio de Tuta en Boyacá que desarrollan actividades de acompañamiento con adultos en la producción agropecuaria, teniendo como parámetro los lineamientos generales que establecen los nuevos conceptos desarrollados por la Ley de infancia y adolescencia, mediante la aplicación de un instrumento estadístico que permitió corroborar la existencia parcial de condiciones anormales para algunos menores campesinos.

Palabras clave: Investigación, menor trabajador, campesino, derecho del menor, producción, desarrollo humano, Sisbén.

Abstract.- A study of the status of minor peasant in the municipality of Tuta in Boyaca who are engaged in activities with adults accompanying agricultural production was carried out, having as a parameter the general outlines which establish the new concepts developed by the Law of childhood and adolescence, through the application of an statistical instrument that allowed to corroborate the partial existence of abnormal conditions for some minor peasants.

Key words: Research, working minor, peasant, minor rights, production, human development, Sisben.

\section{Introducción}

La inexistencia de investigaciones formales sobre el problema de los menores que estudian y trabajan en el sector agrario del municipio de Tuta (Boyacá) y las informaciones fraccionadas entre instituciones que tienen competencias para la atención de la problemática (diagnóstico, estadística, atención e intervención), impiden el reconocimiento de la magnitud del problema y la acción coordinada para su intervención.

Se considera irregular y problemática la situación del menor cuando ejecuta labores riesgosas, no consideradas aptas para este tipo de trabajadores y cuando se desliga de la formación académica, interrumpiendo el proceso de escolaridad. 
También afecta la ejecución de labores que exceden las jornadas establecidas por el Estado, como máximas para el menor que estudia y trabaja. Es también problemática la vinculación laboral del menor al considerar que esta altera los propósitos, ilusiones y necesidades que apuntan a su desarrollo personal.

A partir de estas situaciones que enfrentan los menores del municipio, la investigación se propuso identificar las características del problema, analizar y precisar las limitaciones que se presentan en el cumplimiento de los principios legales para la protección de este segmento de la población del municipio de Tuta.

\section{Materiales y métodos}

Ajustándose a la metodología de aplicación deencuestas, serealizóunapruebapilotocon dos estudiantes del Colegio Nacionalizado Chicamocha, dos del Colegio de Río de Piedras y una estudiante de la escuela El Cruce de la vereda La Hacienda. Según resultados y recomendaciones de la revisora del anteproyecto, se ajustó la redacción con la oficina de trabajo social del Municipio de Tuta y se aplicaron las encuestas en el mes de marzo a 110 menores entre 12 y 16 años residentes de las veredas La Hacienda, Santa Rita, Alisal, Leonera y El Hato. Es de notar que en estas veredas también se realizan actividades mineras de extracción de carbón. Se anularon 12 formularios por errores en las respuestas y una menor rechazó la interacción.
Para evitar posibles desviaciones en las respuestas, aunque luego de aplicar la prueba piloto se efectuaron algunos ajustes en la redacción del texto, se optó por leerle la pregunta al encuestado y en caso de surgir interrogantes al respecto, se le explicaba el sentido de la pregunta.

Se indagó acerca de la existencia de algunas actividades relacionadas con la vinculación de menores a labores productivas agropecuarias por tiempos superiores a las dos horas diarias. Se consideró este límite porque cerca del $50 \%$ de los jóvenes ejecutan tareas del hogar con una duración promedio de dos horas al día. Igualmente se corroboró si existía vinculación de menores a las industrias y las empresas agroindustriales que funcionan en los sectores industriales del municipio.

El panorama social se amplía para algunos menores quienes al llegar a la edad de 18 años, toman la determinación de abandonar su hogar y dedicarse a trabajar en las minas de carbón vecinas o buscar fortuna en ciudades grandes.

Durante tres semanas no consecutivas se recorrieron en horario escolar, varias vías interveredales de zonas del municipio, para identificar la existencia real de menores de edad trabajando. También se entrevistaron autoridades municipales como el Personero, el Alcalde, la Directora de Núcleo y otros funcionarios encargados de preservar los derechos de la población y que son conocedores de posibles quejas acerca de la vinculación indebida del menor al trabajo. 


\section{Resultados}

El 39\% de los menores entrevistados respondieron que trabajan más de 18 horas semanales (Tabla 1), lo que equivale a ejecutar, además de las 30 horas semanales de estudio, actividades de trabajo en el hogar, en casas de parientes o vecinos e incluso de particulares, a cambio de algún pago.

Tabla 1. Horas trabajadas a la semana por los menores encuestados

\begin{tabular}{ccc}
\hline $\begin{array}{c}\text { No. de horas } \\
\text { trabajadas a la } \\
\text { semana }\end{array}$ & $\begin{array}{c}\text { Total de } \\
\text { respuestas }\end{array}$ & $\begin{array}{c}\text { \% de } \\
\text { entrevistados }\end{array}$ \\
\hline 18 & 16 & 19 \\
20 & 6 & 7 \\
21 & 6 & 7 \\
25 & 3 & 3 \\
30 & 3 & 3 \\
TOTALES & $\mathbf{3 4}$ & $\mathbf{3 9}$ \\
\hline
\end{tabular}

Fuente: Encuestas aplicadas a este estudio

LosfuncionariosdelInstituto Colombiano de Bienestar Familiar con sede en Tunja, al ser informados de la situación de los menores trabajadores del municipio, enfatizaron en la necesidad de estudiar minuciosamente el tipo de labores que ejecutaban los menores, evaluar si son o no apropiadas para su desarrollo físico y psicológico y si estos menores pueden ejecutar tareas que impliquen esfuerzos prolongados. Es también una costumbre considerada culturalmente válida, que los menores se vinculen a las actividades del hogar para colaborar en la generación de ingresos o para reemplazar a los adultos en algunas actividades del hogar.

Un porcentaje de menores campesinos del municipio de Tuta respondieron que deben levantarse a la madrugada a desarrollar ciertas labores antes de asistir al colegio y continuarlas al regresar a su casa luego de cumplir con la jornada habitual de estudio.

Estos menores son aquellos que manifestaron trabajar jornadas de más de veinte horas semanales. En las Instituciones Educativas visitadas, el $20 \%$ de los menores manifestaron que ejecutaban tareas aparte de su actividad de estudio, que les consumían en promedio cuatro horas al día o más.

Los menores entrevistados no solo trabajan en su propio núcleo familiar colaborando con el aseguramiento de la subsistencia sino que algunos de ellos (25\%) también trabajan con parientes o vecinos y en ocasiones reciben un pago por la labor realizada. 
Tabla 2. Actividades realizadas por los menores encuestados

\begin{tabular}{lcc}
\hline \multicolumn{1}{c}{ TAREA } & $\begin{array}{c}\text { Total de } \\
\text { respuestas }\end{array}$ & $\begin{array}{c}\text { \% de } \\
\text { entrevistados }\end{array}$ \\
\hline Cuidado de animales & 62 & 25 \\
$\begin{array}{l}\text { Labores de preparación de } \\
\text { la tierra, siembra y cosecha }\end{array}$ & 78 & 30 \\
Fumigar & 13 & 5 \\
Transporte de los productos & 15 & 6 \\
$\begin{array}{l}\text { Comercialización de los } \\
\text { productos agropecuarios }\end{array}$ & 17 & 7 \\
Oficios domésticos & 35 & 14 \\
Manejo de maquinaria agrícola & 3 & 1 \\
Otras actividades & 30 & 12 \\
\hline
\end{tabular}

Fuente: Encuestas aplicadas a este estudio

Entre los trabajos habituales para la mayoría de los menores entrevistados, el $25 \%$ participa en actividades relacionadas con el cuidado de animales como ordeño, traslado de un potrero a otro, "asegurar los terneros", y el 30\% ejecutan labores relacionadas con la preparación del terreno para siembra y con la cosecha (Tabla 2).

En el grupo de niñas, son habituales las tareas relacionadas con oficios del hogar, aunque muchas de ellas participan también en las tareas de cuidado de animales, siembra y cosecha.

Tabla 3. Dedicación al estudio y al trabajo

\begin{tabular}{|l|c|c|}
\hline \multicolumn{1}{|c|}{ PREGUNTA } & $\begin{array}{c}\text { Total de } \\
\text { respuestas }\end{array}$ & $\begin{array}{c}\text { \% de } \\
\text { entrevistados }\end{array}$ \\
\hline Siempre estudio & 98 & 81 \\
\hline Dejo de estudiar todo el año & 5 & 4 \\
\hline $\begin{array}{l}\text { No estudio en época de } \\
\text { siembra, de aporque y de } \\
\text { cosecha }\end{array}$ & 3 & 3 \\
\hline $\begin{array}{l}\text { Dejo de estudiar solo } \\
\text { algunos días al año y no por } \\
\text { estar trabajando }\end{array}$ & 14 & 12 \\
\hline
\end{tabular}

Fuente: Encuestas aplicadas a este estudio

E1 7\% de los entrevistados faltan uno o varios días por estar dedicados a labores relacionadas con ejecuciones de trabajos (Tabla 3). Cerca del 8\% reciben 
alguna forma de pago por los trabajos realizados bajo órdenes de parientes o de particulares. Algunos menores trabajan ocasionalmente a órdenes de parientes, recibiendo un pago en especie y generalmente desarrollan esta actividad como contraprestación por vivir con sus parientes o porque son órdenes de sus padres.

La vinculación laboral según las condiciones que determina la ley 1098 de 2006, se redujo apreciablemente en el municipio de Tuta durante los últimos diez años por la intervención de ECOCARBÓN, Familias en Acción y la Personería. Muy ocasionalmente la Alcaldía y el Instituto Colombiano de Bienestar Familiar ICBF exigen condiciones laborales que deben ser analizadas con profundidad, en la medida en que por lo menos el 39\% de los menores encuestados trabajan más de 18 horas a la semana, tiempo de dedicación que supera los límites que la ley establece para la jornada laboral de los menores trabajadores.

Existe vinculación al trabajo de un porcentaje de menores que simultáneamente estudian y trabajan, lo cual debe ser objeto de estudio centrado en las condiciones en las que este trabajo se ejecuta. Se encontró que para varios menores existe prolongada dedicación al trabajo, contraria al Código del menor.

La comprensión básica sobre condiciones para la satisfacción de las necesidades de los menores campesinos en el municipio de Tuta, tendría que relacionarse con el reconocimiento de que la sociedad requiere el sostenimiento y preservación de los mecanismos que posibiliten permanentemente la satisfacción de las necesidades humanas (Sen, 2000).

Este razonamiento lleva a entender que los recursos entregados a las unidades familiares a través de programas como Familias en Acción, protección a las personas de la tercera edad y otros, realmente no se pueden considerar como mecanismos idóneos que permitan la solución permanente de las necesidades de un grupo de personas.

Los datos del Sisbén muestran que la totalidad de las unidades familiares residentes en estas veredas son personas pertenecientes a los niveles uno y dos del Sisbén y que, adicionalmente, los sistemas de estratificación los clasifican según condiciones de vivienda $\mathrm{y}$ entorno, en los estratos uno y dos.

Estas condiciones llevan a que las posibilidadesparaaccederalasatisfacción de las necesidades estén restringidas por los problemas financieros que enfrentan las unidades familiares.

Desde la perspectiva de las teorías de desarrollo humano, puede considerarse que existen niveles elevados de carencias que son apenas parcialmente solucionadas con acciones como el aseguramiento en el régimen subsidiado que, aunque ofrece servicios médicos con calidad cuestionable, pueden incidir en el mejoramiento de la esperanza de vida (García et al., 2000).

Es importante entender que las acciones ejecutadas en el plan de desarrollo municipal (Municipio de Tuta, 2008) obedecen principalmente al paradigma de las necesidades básicas insatisfechas, 
pero excluyen niveles de carencias que van más allá del acceso a servicios públicos, al empleo, al aseguramiento en el sistema de salud, a vivienda, a recreación y a educación.

El índice de desarrollo humano como instrumento que mide el progreso nacional promedio, al incluir los índices de desarrollo de género y potenciación de género, puede constituirse en un instrumento que sobrepase los alcances de las Necesidades Básicas Insatisfechas (NBI). Por ejemplo, se trata de reconocer en la productividad no el aumento de la producción de valor por unidad de tiempo sino el aumento de la capacidad de las personas para contribuir al crecimiento en el que participan los logros orientados a la cualificación del capital cívico y del capital humano (Max-Neef, 1998; Maslow, 1982; Batthyány et al., 2004).

Las condiciones que permitan superar el desarrollo intelectual desigual son todavía un propósito lejano dentro de las ejecuciones de política pública adelantadas por la administración local y los gobiernos nacional y departamental.

\section{Discusión y Conclusiones}

Los derechos de los menores son la puerta de entrada al desarrollo humano sostenible, y su cumplimiento garantiza el relevo generacional y contribuye a la gobernabilidad y la democracia. La calidad de vida en la niñez tiene importancia no solo para lo que ocurra en la niñez, sino también por sus efectos en la vida adulta, ya que incide en la salud y el desempeño mental, físico y productivo. Las capacidades que poseen los adultos están condicionadas por la experiencia y las vivencias que tuvieron cuando niños y en general, como menores de edad.

En el desarrollo del estudio se identificó que entre 14 y $20 \%$ de los menores que estudian, deben simultáneamente ejecutar tareas iguales o superiores a cuatro horas diarias, creándose condiciones que pueden ser percibidas como irregulares para ellos y que los análisis psicológico y sociológico, pueden mostrar efectos nocivos en su desarrollo físico y psicosocial.

En los resultados de la indagación efectuada a los menores de la escuela Santa Rita, sector El Cruce, se halló que por lo menos el 14\% de los encuestados afrontan condiciones irregulares, derivadas de extender el apoyo al trabajo de la unidad familiar a actividades relacionadas con la producción agrícola, el cuidado de animales y los oficios del hogar.

\section{Referencias}

1) Batthyány, K., Cabrera, M. \& Macadar, D. (2004). La pobreza y la desigualdad en América. Cuadernos Ocasionales, 4. Recuperado de http://www.bvsde.paho. org/bvsacd/cd63/cuadernos04.pdf.

2) Código del menor. Ley 1098,8 de noviembre de 2006. Disponible en: http://www.encolombia.com/ derecho/derecho-codigomenor1.htm.

3) Colombia. Constitución política, Art. 58.

4) García, P., Lazzari, L. \& Machado, E. (2000). Una propuesta Fuzzy para definir indicadores de pobreza. Cuadernos del CIMBAGE (3). 
Disponible en http://redalyc.uamex. mx/pdf/462/46200302.pdf

5) Maslow, A. (1982). Motivación y personalidad. Madrid, España: Díaz de Santos.

6) Max-Neef, M. (1998). Desarrollo a escala humana: Una opción para el futuro. Barcelona, España: Icaria.
7) Municipio de Tuta. (2008). Plan de Desarrollo 2008-2011.

8) Sen, A. (2000). Desarrollo y libertad ( $2^{\mathrm{a}}$ edic.). Barcelona, España: McGraw-Hill.

Recibido: 20 de agosto de 2011 Aceptado: 30 de noviembre de 2011 